\title{
Amorphous aluminum-carbide and aluminum-magnesium-carbide nanoparticles from gas phase activation of trimethylaluminum and octamethyldialuminummagnesium using simultaneous spatially and temporally focused ultrashort laser pulses.
}

\author{
Katharine Moore Tibbetts, ${ }^{1}$ Johanan Odhner, ${ }^{2}$ Shivaiah Vaddypally, ${ }^{2}$ Bezhad \\ Tangyesh, ${ }^{2}$ Elizabeth B. Cerkez, ${ }^{2}$ Daniel R. Strongin, Michael J. Zdilla, ${ }^{2 *}$ Robert J. \\ Levis $^{2 *}$
}

1. Current Address: Department of Chemistry, Virginia Commonwealth University, 1001 W. Main St., Richmond, VA 23284

2. Department of Chemistry, Temple University, 1901 N. $13^{\text {th }}$ St., Philadelphia, PA 19122

KEYWORDS : femtosecond laser pulse, nanoparticle, aluminum, aluminum carbide

ABSTRACT: Gas-phase laser irradiation of head-space $\mathrm{AlMe}_{3}(\mathrm{~g})$ using simultaneous spatially and temporally focused pulses results in nucleation of Al-rich nanoparticles, which fall from the gas phase into the liquid-phase precursor to give a black suspension of nanoparticles. Isolation of the particles and characterization by transmission electron microscopy, X-ray dispersive energy, vibrational, and X-ray photoelectron spectroscopy identify the material as amorphous aluminum- and carbide-containing nanoparticles. An analogous experiment using $\mathrm{Al}_{2} \mathrm{MgMe}_{8}$ as a precursor results in nanoparticles containing both $\mathrm{Al}$ and $\mathrm{Mg}$ atoms.

Bulk [1, 2] and nanophases [3-6] of elemental aluminum and magnesium alloys have implications for structural and energetic materials such as inorganic nano-thermite, $[7,8]$ and for plasmonic materials $[9-$ 11]. Aluminum carbide $\left(\mathrm{Al}_{4} \mathrm{C}_{3}\right)$ and heterostructures thereof have implication for strong structural materials.[12-15] Elemental aluminum nanoparticles have been synthesized by a number of methods, including laser ablation of $\mathrm{Al}(\mathrm{s}),[16,17]$ chemical reduction of $\mathrm{Al}^{3+}$ precursors,[18] chemical activation of alanes $\left(A \mid R_{3}\right),[19]$ aerosol techniques,[20, 21] and electrically exploding wires.[22] Aluminum carbide nanoparticles are little explored, and limited to a few reports relying on mechanochemical synthesis of $\mathrm{Al} / \mathrm{C}$ nanocomposites by milling of $\mathrm{Al}(\mathrm{s})$ and $\mathrm{C}(\mathrm{s})$ (graphite) particles simultaneously.[23-25] Reports of aluminum carbide 1-D and 2-D nanomaterials are also known.[26-28] To our knowledge, all reports of nano aluminum carbide phases occur under thermal or mechanochemical conditions to give nanocrystalline $\mathrm{Al}_{4} \mathrm{C}_{3}$ phases.

Since alloys of $\mathrm{Mg}$ and $\mathrm{Al}$ are of broad interest for structural and energetic metal-based materials, [3-8] a significant goal of our research is to generate mixed-metal or alloy nanoparticles using molecular precursors that contain the desired mixture of metal elements. To generate novel mixed-metal nanomaterials, we are exploring the rapid condensation of gas-phase elements into nanoparticles on timescales faster than phase separation (i.e., to template the generation of metal-based nanoparticles in 
the gas phase). We have been exploring a novel approach to nanoparticle synthesis using simultaneous spatial and temporal focusing (SSTF) of ultrashort laser pulses to provide electromagnetic-field-induced nucleation of nanoparticles.[29-32] The SSTF approach involves spectrally and temporally dispersing ultrashort laser pulses with a grating pair and recombining the spectral components with a short focal length lens, thus spatially and temporally focusing the laser pulses.[33] This approach allows for the generation of intense laser pulses exquisitely localized in time ( $36 \mathrm{ps}$ ), and space (about a $0.00042 \mathrm{~mm}^{3}$ volume of plasma), and has already demonstrated utility in materials processing.[34, 35] This localization of beam intensity by SSTF is in contrast to geometrically focusing ultrashort laser pulses, which results in detrimental nonlinear optical effects that limit the achievable laser intensity in the sample,[36] as well as etch the wall of the reaction cell.[30] The SSTF approach permits rapid atomization of precursors in the "plasma reactor" followed by diffusion of atomized precursors into the relatively cool surrounding regions of the reactor where they condense into nanoparticles in the gas phase. We present in this report the preparation of amorphous aluminum carbide nanoparticles from $\mathrm{AlMe}_{3}$ and amorphous aluminum/magnesium-containing nanoparticles from $\mathrm{Al}_{2} \mathrm{MgMe}_{8}$ using SSTF. $\mathrm{AlMe}_{3}$ has been explored as a precursor for chemical vapor deposition (CVD)[37] and ALD[38] of aluminum-based films.

Colorless $\mathrm{AlMe}_{3}(200 \mu \mathrm{L})$ in an evacuated cuvette at room temperature has a vapor pressure of $\sim 9$ torr.[39] The vapor within the cuvette is irradiated by the SSTF laser (pulse energy $2 \mathrm{~mJ}$, center wavelength $790 \mathrm{~nm}$, pulse duration $36 \mathrm{ps}$ )[29] with the focal point centered in the $\mathrm{AlMe}_{3}(\mathrm{~g})$ headspace at the center of the cuvette. Upon irradiation, black material begins to form, giving the cuvette a smoky appearance. The solid formed in the headspace rains down into the $\mathrm{AlMe}_{3}$ precursor below, and deposits on the walls of the cuvette as well. Longer irradiation times result in heating of the cuvette and sample, which results in an obligate raise of the vapor pressure of $\mathrm{AlMe}_{3}$ increasing the rate of precursor processing. Despite the fact that the laser beam is defocused near the walls of the cuvette, the deposited energy is sufficient to dislodge the solid material as it collects on the sides of the cuvette, resulting in some further ablation and processing of this material post-formation at longer exposure times. After completion of irradiation, the cuvette is coated by black material, with a brown-black suspension of nanoparticles in unreacted $\mathrm{AlMe}_{3}(\mathrm{I})$. Gas phase analysis of headspace gas by mass spectroscopy[40] reveals the formation of $\mathrm{H}_{2}$, methane, acetylene, ethylene, ethane, and propene as side products of the reaction (Fig. S1).

After irradiation for five minutes (600 J deposited in total), the solid is isolated by removal of unreacted $\mathrm{AIMe}_{3}$ in vacuo, and analyzed by TEM, which reveals individual and agglomerated nanoparticles approximately 10-40 $\mathrm{nm}$ in diameter. Longer irradiation times (30 $\mathrm{min}$ ) resulted in further fusion to give larger particles, dozens of microns in size. Energy-dispersive X-ray spectroscopy (EDS) reveals a similar spectrum for both samples, which possesses a large aluminum peak, confirming the presence of significant quantities of aluminum in the nanomaterial. Additionally, a significant oxygen peak is observed, attributed to surface modification by $\mathrm{O}_{2}$ or $\mathrm{H}_{2} \mathrm{O}$ in air (discussed further below) during postsynthesis handling. A very small carbon peak is present as well.

Surprisingly, this material--whether taken from the walls or the bottom of the cuvette, and regardless of exposure time--does not give Bragg diffraction of $\mathrm{X}$-rays, suggesting it is an amorphous material. The 
powder pattern of the material is featureless except for a small unidentified, unstable phase that permanently disappears upon heating to $500{ }^{\circ} \mathrm{C}$, which may be contaminant $\mathrm{Al}(\mathrm{OH})_{3}$, which calcines upon heating, giving a truly featureless powder pattern (Figure S3). Upon excessive heating at $700{ }^{\circ} \mathrm{C}, \mathrm{a}$ small amount of a graphitic phase appears by X-ray diffraction, suggesting some carbonaceous component within or on the surface of the particle sample. Examination of the particles by Raman spectroscopy confirms the presence of aliphatic (alkane) C-H stretches (T-band), as well as amorphous (D-band) and crystalline (G-band) graphitic material. Upon heating, the T-band decreases, and the Dand G-bands increase in intensity, suggesting further formation of graphitic material from the aliphatic carbonaceous contaminants. (Fig. S4). The presence of graphitic carbon is further supported by X-ray photoelectron spectroscopy, which shows the presence of elemental carbon on the particle surface (Fig. S7).

Annealing of the particles at these temperatures does not result in appearance of the Bragg pattern of $\mathrm{Al}(\mathrm{s})\left(\mathrm{mp} 660^{\circ} \mathrm{C}\right)$ suggesting that these particles are not elemental aluminum. Though the particles are synthesized under air-free conditions, the EDS spectrum suggests the presence of a significant amount of oxygen, and there is a carbon peak as well, suggesting aluminum carbide, contaminated by oxygen could be a possibility. It is worthwhile to note that $\mathrm{Al}_{4} \mathrm{C}_{3}$ is water sensitive, hydrolyzing to $\mathrm{Al}_{2} \mathrm{O}_{3}$ and $\mathrm{CH}_{4}$,[41] and so exposure of $\mathrm{Al}_{4} \mathrm{C}_{3}$ nanoparticles to air-moisture could account for the large oxygen content. Indeed, the EDS spectrum of commercial $\mathrm{Al}_{4} \mathrm{C}_{3}$ had similar intensities of $\mathrm{Al}$ and $\mathrm{C} K \alpha$ peaks as in the isolated nanomaterial (Figure S6-S8), consistent with similar composition for the two materials, although the commercial sample has lower oxygen content due to slower hydrolysis and a lower surface area to volume ratio.

$\mathrm{Al}_{2} \mathrm{O}_{3}$ and $\mathrm{Al}_{4} \mathrm{C}_{3}$ both possess broad bands in the infrared spectrum in the range of $200-800 \mathrm{~cm}^{-1}$ with slightly different line shapes, and absorption maxima at $650 \mathrm{~cm}^{-1}$ and $704 \mathrm{~cm}^{-1}$ respectively. Examination of the synthesized nanoparticles by ATR FTIR shows a strong, broad band centered at $714 \mathrm{~cm}^{-1}$ most consistent with $\mathrm{Al}_{4} \mathrm{C}_{3}$, suggesting that the bulk of the particle may be better described as amorphous aluminum carbide (Figure $\mathrm{S} 5$ )

To determine the composition of the particles, we turned to X-ray photoelectron spectroscopy (XPS).[42] Figure S10 illustrates an Al 2p peak centered at $75.4 \mathrm{eV}$. Based on a comparison of this value to those associated with Al oxide $(75.9 \mathrm{eV})$, Al carbide $(75.0 \mathrm{eV})$, and Al metal $(73.0 \mathrm{eV})$ with an oxide coating $(75.9 \mathrm{eV})$ suggest that the nanoparticles likely have contributions from both aluminum carbide and oxide, the latter being from air-exposure during handling. Due to the lack of spectral weight near 73 $\mathrm{eV}$ in the laser-processed nanoparticle data, these measurements rule out the presence of metallic aluminum within the particles. While aluminum carbide is known to be slowly reactive with water,[41] the rapid reaction of the particles with $\mathrm{O}_{2}$ suggests they are highly reducing. Indeed, in some instances, we observed these particles to ignite upon scraping with a spatula. Sputtering away the surface of the particles using an ion gun reveals the presence of carbide in the interior of the particle based upon the carbon 1s XPS spectrum (Fig. S7).

The combined spectroscopic and analytical techniques suggest the resulting particles are best described as amorphous aluminum carbide with a graphitic coating. The approach of SSTF activation is consistent 
with the formation of amorphous solids since rapidly formed $\mathrm{Al}(\mathrm{g}), \mathrm{C}(\mathrm{g})$, and $\mathrm{H}(\mathrm{g})$ atoms produced in the gas phase via the SSTF pulse would diffuse to the relatively cool cuvette atmosphere where they would rapidly condense to solids. This rapid formation of the solid phase is presumably too fast to permit crystal nucleation and growth, and results instead in amorphous particles. Alternatively, impure mixtures of carbon-based species (carbide, graphene, hydrocarbons) could disfavor separation into crystalline phases.

To see if this laser-processing approach permits the introduction of mixtures of metal ions, we prepared the volatile solid octamethyldialuminummagnesium $\left(\mathrm{Al}_{2} \mathrm{MgMe}_{8}\right),[43,44]$ which has a vapor pressure of $\sim 0.2$ torr at room temperature according to our measurements using a capacitance bridge manometer. Irradiation of this material using SSTF pulses gave black nanoparticles with a similar morphology, though larger (100-200 nm) than the all-Al particles. EDS on these materials demonstrates a significant proportion of both $\mathrm{Al}$ and $\mathrm{Mg}$ atoms. EDS spectroscopy also indicates the presence of $\mathrm{O}$ and $\mathrm{C}$ atoms in similar amounts to those observed in the EDS spectra of amorphous aluminum carbide nanoparticles.

In summary, we report the formation of amorphous Al- and Al-Mg-containing nanoparticles from gas phase precursors using SSTF laser processing. Future work will involve the construction of a flow cell for greater product yield, and which may be purged with gaseous, reducing co-substrates (e.g., $\mathrm{H}_{2}$ ) to promote the formation of elemental metal nanoparticles.

Corresponding Author

*rjlevis@temple.edu

*mzdilla@temple.edu

\section{Funding Sources}

Support of this research by the Army Research Laboratory through contract W911NF-10-2-009 is gratefully acknowledged. The authors are also grateful for an NSF instrumentation grant (CHE-0923077) for the JEOL JEM-1400 TEM used in this research.

\section{Acknowledgment}

Prof. David R. Dalton is gratefully acknowledge for assistance with vapor pressure measurements.

\section{Abbreviatons}

SSTF - Simultaneous Spatially and Temporally Focused, TEM - Transmission Electron Microscopy, EDS Energy Dispersive X-ray Spectroscopy, XPS - X-ray Photoelectron Spectroscopy. 


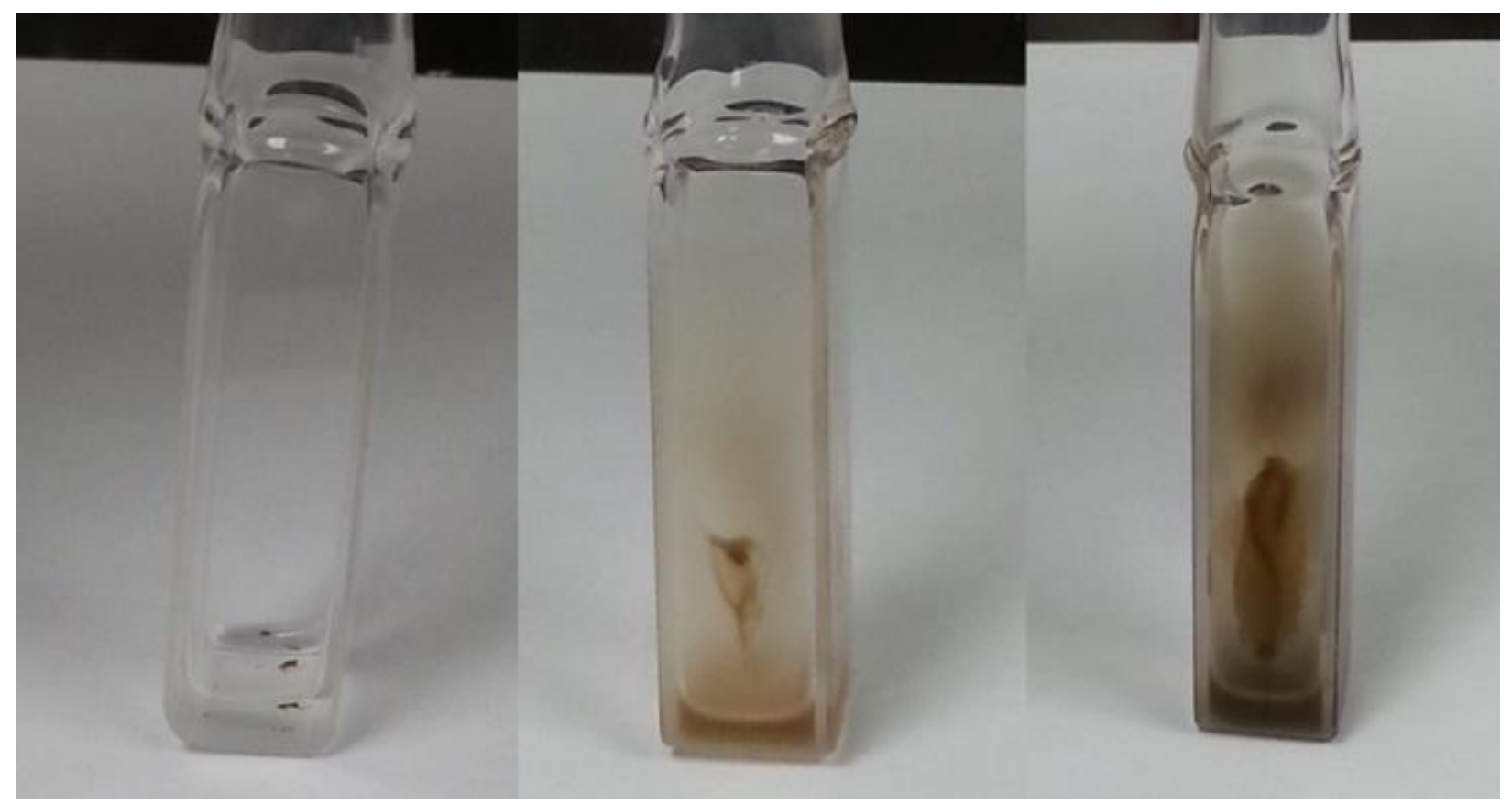

Figure 1. Cuvette with ca. $100 \mu \mathrm{L} \mathrm{AlMe}$ appearance at various stages of SSTF processing. Left: Before irradiation. Middle: After 5 minutes. Right: After 30 minutes. 

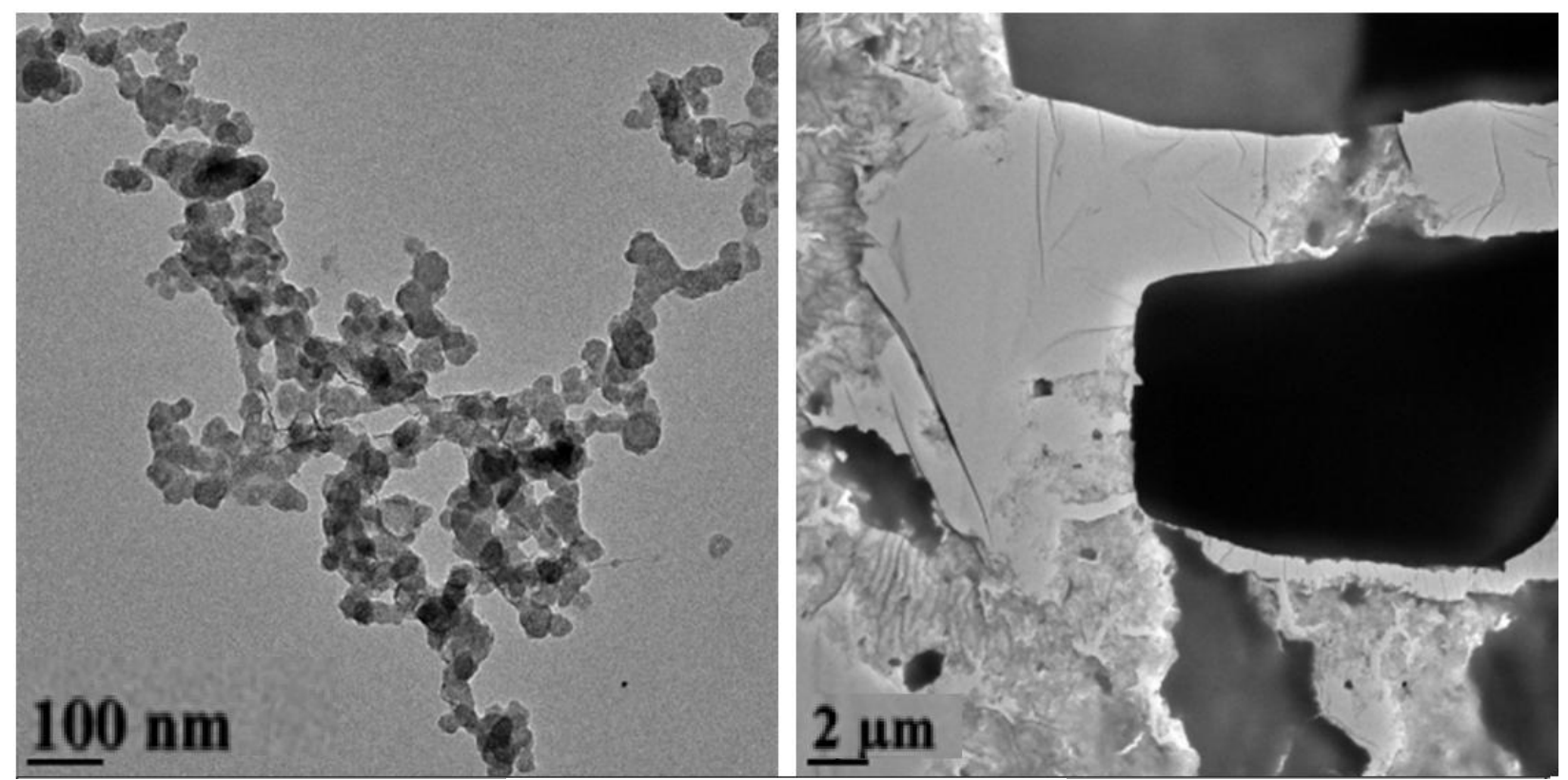

\section{AlKa}

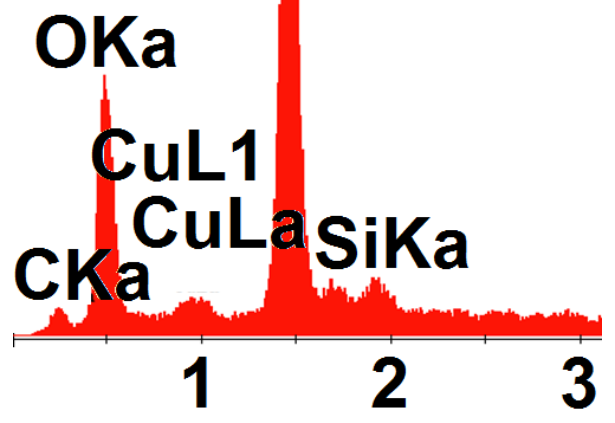

Figure 2. TEM images of nanoparticles. Left: after 5 minutes irradiation $(600 \mathrm{~J})$. Right after 30 minutes irradiation $(3600 \mathrm{~J})$. Bottom (EDS spectrum of nanoparticles confirming significant aluminum content. 


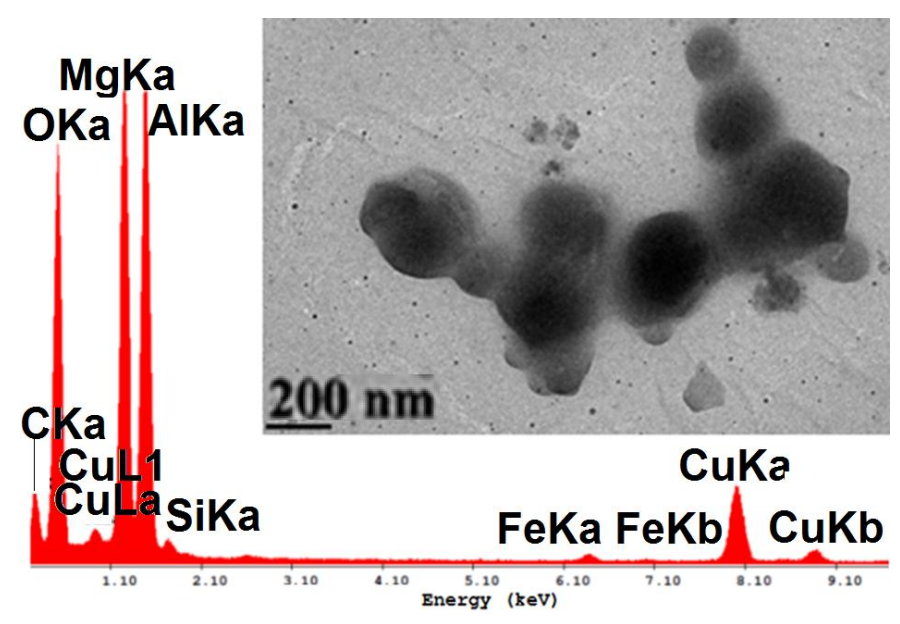

Figure 3. TEM image of nanoparticles (inset) formed by irradiation by SSTF, and EDS spectrum of nanoparticles confirming significant aluminum and magnesium content. 


\section{References}

[1] T. Dursun, C. Soutis, Recent developments in advanced aircraft aluminium alloys, Materials \& Design, 56 (2014) 862-871.

[2] Y. Wang, W. Jiang, X.F. Zhang, H.Y. Liu, Y.Q. Liu, F.S. Li, Energy release characteristics of impactinitiated energetic aluminum-magnesium mechanical alloy particles with nanometer-scale structure, Thermochimica Acta, 512 (2011) 233-239.

[3] I. Marek, D. Vojtěch, A. Michalcová, T.F. Kubatík, High-strength bulk nano-crystalline silver prepared by selective leaching combined with spark plasma sintering, Materials Science and Engineering: A, 627 (2015) 326-332.

[4] H. Ahamed, V. Senthilkumar, Experimental investigation on newly developed ultrafine-grained aluminium based nano-composites with improved mechanical properties, Materials \& Design, 37 (2012) 182-192.

[5] N.H. Hoang, O.S. Hopperstad, O.R. Myhr, C. Marioara, M. Langseth, An improved nano-scale material model applied in axial-crushing analyses of square hollow section aluminium profiles, Thin-Walled Structures, 92 (2015) 93-103.

[6] A. Bacciochini, M.I. Radulescu, Y. Charron-Tousignant, J. Van Dyke, M. Nganbe, M. Yandouzi, J.J. Lee, B. Jodoin, Enhanced reactivity of mechanically-activated nano-scale gasless reactive materials consolidated by coldspray, Surface \& Coatings Technology, 206 (2012) 4343-4348.

[7] X. Zhou, M. Torabi, J. Lu, R.Q. Shen, K.L. Zhang, Nanostructured Energetic Composites: Synthesis, Ignition/Combustion Modeling, and Applications, Acs Applied Materials \& Interfaces, 6 (2014) 30583074.

[8] D.R. Yan, Y.C. Dong, Y. Yang, L. Wang, X.G. Chen, J.N. He, J.X. Zhang, Microstructure Characterization of the FeAl2O4-Based Nanostructured Composite Coating Synthesized by Plasma Spraying Fe2O3/Al Powders, Journal of Thermal Spray Technology, 20 (2011) 1269-1277.

[9] J. Martin, J. Plain, Fabrication of aluminium nanostructures for plasmonics, Journal of Physics DApplied Physics, 48 (2015).

[10] H.W. Liu, F.C. Lin, S.W. Lin, J.Y. Wu, B.T. Chou, K.J. Lai, S.D. Lin, J.S. Huang, Single-Crystalline Aluminum Nanostructures on a Semiconducting GaAs Substrate for Ultraviolet to Near-Infrared Plasmonics, Acs Nano, 9 (2015) 3875-3886.

[11] M.W. Knight, N.S. King, L.F. Liu, H.O. Everitt, P. Nordlander, N.J. Halas, Aluminum for Plasmonics, Acs Nano, 8 (2014) 834-840.

[12] W.K. Pang, I.M. Low, Understanding and improving the thermal stability of layered ternary carbides in ceramic matrix composites, Woodhead Publ Ltd, Cambridge, 2014.

[13] D.P. Riley, E.H. Kisi, The design of crystalline precursors for the synthesis of $M(n-1) A X(n)$ phases and their application to Ti3AIC2, Journal of the American Ceramic Society, 90 (2007) 2231-2235.

[14] L.Y. Zheng, J.Y. Wang, J.X. Chen, M.Y. Liu, Y.J. Sun, Y.C. Zhou, Preparation, Microstructure, and Mechanical Properties of Nb4AIC3-Nb-5(Si, Al)(3) Composites, Journal of the American Ceramic Society, 96 (2013) 365-368.

[15] S. Nimityongskul, M. Jones, H. Choi, R. Lakes, S. Kou, X.C. Li, Grain refining mechanisms in Mg-Al alloys with Al4C3 microparticles, Materials Science and Engineering a-Structural Materials Properties Microstructure and Processing, 527 (2010) 2104-2111.

[16] S. Lee, H.J. Jung, J.H. Shin, M.Y. Choi, Production of Size Controlled Aluminum and Alumina Nanoparticles via Pulsed Laser Ablation in Water, Journal of Nanoscience and Nanotechnology, 12 (2012) 8900-8903.

[17] M. Ullmann, S.K. Friedlander, A. Schmidt-Ott, Nanoparticle formation by laser ablation, Journal of Nanoparticle Research, 4 (2002) 499-509. 
[18] S. Ghanta, K. Muralidharan, Chemical synthesis of aluminum nanoparticles, Journal of Nanoparticle Research, 15 (2013) 1-10.

[19] M.J. Meziani, C.E. Bunker, F. Lu, H. Li, W. Wang, E.A. Guliants, R.A. Quinn, Y.-P. Sun, Formation and Properties of Stabilized Aluminum Nanoparticles, ACS Applied Materials \& Interfaces, 1 (2009) 703-709. [20] V.B. Storozhev, A.N. Zhigach, M.L. Kuskov, M.N. Larichev, I.O. Leipunsky, V.V. Artemov, O.M. Zhigalina, The synthesis of nanosized aluminum particles by the levitation-in-flow method and an analysis of their particle size distribution, Nanotechnol Russia, 4 (2009) 182-187.

[21] R.J. Helmich, K.S. Suslick, Chemical Aerosol Flow Synthesis of Hollow Metallic Aluminum Particles, Chemistry of Materials, 22 (2010) 4835-4837.

[22] K. Jayaraman, K.V. Anand, D.S. Bhatt, S.R. Chakravarthy, R. Sarathi, Production, Characterization, and Combustion of Nanoaluminum in Composite Solid Propellants, Journal of Propulsion and Power, 25 (2009) 471-481.

[23] A. Santos-Beltrán, R. Goytia-Reyes, H. Morales-Rodriguez, V. Gallegos-Orozco, M. Santos-Beltrán, F. Baldenebro-Lopez, R. Martínez-Sánchez, Characterization of Al-Al4C3 Nanocomposites Produced By Mechanical Milling, Materials Characterization.

[24] A. Santos-Beltrán, M. Miki-Yoshida, F. Alvarado-Hernández, S. Haro-Rodríguez, V. Gallegos-Orozco, Aluminum Carbide Nanoparticles Produced By Mechanical Milling, Microsc. Microanal., 15 (2009) 13261327.

[25] A.N. Streletskii, I.V. Povstugar, A.B. Borunova, S.F. Lomaeva, P.Y. Butyagin, Mechanochemical activation of aluminum. 4. Kinetics of mechanochemical synthesis of aluminum carbide, Colloid J, 68 (2006) 470-480.

[26] C.N. He, N.Q. Zhao, C.S. Shi, S.Z. Song, Fabrication of aluminum carbide nanowires by a nanotemplate reaction, Carbon, 48 (2010) 931-938.

[27] H.F. Zhang, A.C. Dohnalkova, C.M. Wang, J.S. Young, E.C. Buck, L.S. Wang, Lithium-assisted selfassembly of aluminum carbide nanowires and nanoribbons, Nano Letters, 2 (2002) 105-108.

[28] Y. Sun, H. Cui, L. Gong, J. Chen, C.X. Wang, Synthesis of AI4C3 nanowalls via thermal evaporation and potential application in vacuum microelectronic devices as cold electron emitters, Crystengcomm, 14 (2012) 7951-7957.

[29] B. Tangeysh, K. Moore Tibbetts, J.H. Odhner, B.B. Wayland, R.J. Levis, Gold Nanoparticle Synthesis Using Spatially and Temporally Shaped Femtosecond Laser Pulses: Post-Irradiation Auto-Reduction of Aqueous [AuCl4]-, The Journal of Physical Chemistry C, 117 (2013) 18719-18727.

[30] J.H. Odhner, K.M. Tibbetts, B. Tangeysh, B.B. Wayland, R.J. Levis, Mechanism of Improved Au Nanoparticle Size Distributions Using Simultaneous Spatial and Temporal Focusing for Femtosecond Laser Irradiation of Aqueous KAuCl4, The Journal of Physical Chemistry C, 118 (2014) 23986-23995.

[31] S.L. Shumlas, K. Moore Tibbetts, J.H. Odhner, D.A. Romanov, R.J. Levis, D.R. Strongin, Formation of carbon nanospheres via ultrashort pulse laser irradiation of methane, Materials Chemistry and Physics, 156 (2015) 47-53.

[32] B. Tangeysh, K. Moore Tibbetts, J.H. Odhner, B.B. Wayland, R.J. Levis, Triangular Gold Nanoplate Growth by Oriented Attachment of Au Seeds Generated by Strong Field Laser Reduction, Nano Letters, 15 (2015) 3377-3382.

[33] D. Oron, Y. Silberberg, Spatiotemporal coherent control using shaped, temporally focused pulses, Opt. Express, 13 (2005) 9903-9908.

[34] J.U. Thomas, E. Block, M. Greco, A. Meier, C.G. Durfee, J.A. Squier, S. Nolte, A. Tunnermann, Simultaneously spatially and temporally focusing light for tailored ultrafast micro-machining, Frontiers in Ultrafast Optics: Biomedical, Scientific, and Industrial Applications Xiv, 8972 (2014).

[35] J. Squier, J. Thomas, E. Block, C. Durfee, S. Backus, High average power Yb:CaF2 femtosecond amplifier with integrated simultaneous spatial and temporal focusing for laser material processing, Applied Physics a-Materials Science \& Processing, 114 (2014) 209-214. 
[36] W. Liu, S. Petit, A. Becker, N. Aközbek, C.M. Bowden, S.L. Chin, Intensity clamping of a femtosecond laser pulse in condensed matter, Optics Communications, 202 (2002) 189-197.

[37] D.K. Russell, Gas-phase pyrolysis mechanisms in organometallic CVD, Chemical Vapor Deposition, 2 (1996) 223-\&.

[38] R.L. Puurunen, Surface chemistry of atomic layer deposition: A case study for the trimethylaluminum/water process, Journal of Applied Physics, 97 (2005).

[39] A.D. Zorin, A.M. Kutin, T.V. Kuznetsova, K.N. Klimov, I.A. Feshchenko, Bulk and surface-properties of lower alkyl derivatives of non-transition elements. 2. Trimethylaluminum, triethylaluminum and tripropylaluminum. , Zhurnal Fizicheskoi Khimii, 58 (1984) 2618-2620.

[40] T. Bohinski, K.M. Tibbetts, M. Tarazkar, D.A. Romanov, S. Matsika, R.J. Levis, Measurement of ionic resonances in alkyl phenyl ketone cations via infrared strong field mass spectrometry, Journal of Physical Chemistry A. , 117 (2013) 12374-12381.

[41] G. Charlot, Qualitative Inorganic Analysis: A New Physicochemical Approach, Cambridge University Press, Cambridge, UK, 1938.

[42] C. Hinnen, D. Imbert, J.M. Siffre, P. Marcus, An in situ XPS study of sputter-deposited aluminium thin films on graphite, Applied Surface Science, 78 (1994) 219-231.

[43] P.J. Bailey, C.M.E. Dick, S. Fabre, S. Parsons, Synthesis and characterisation of magnesium methyl complexes with monoanionic chelating nitrogen donor ligands and their reaction with dioxygen, Journal of the Chemical Society, Dalton Transactions, (2000) 1655-1661.

[44] J.L. Atwood, G.D. Stucky, Stereochemistry of polynuclear compounds of the main group elements. VII. Structure of octamethyldialuminummonomagnesium, Journal of the American Chemical Society, 91 (1969) 2538-2543. 